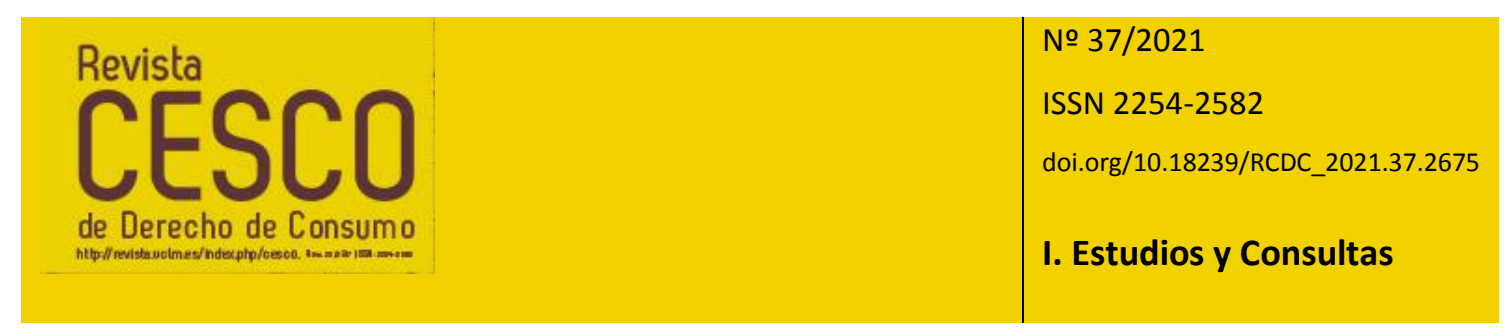

\title{
LA RESTITUCIÓN DEL GASTO DE TASACIÓN Y LA POSICIÓN DE LOS CONSUMIDORES QUE YA HUBIERAN OBTENIDO UNA SENTENCIA FIRME*
}

\author{
Alicia Agüero Ortiz** \\ Profesora Ayudante Doctora de Derecho Civil \\ Universidad Autónoma de Madrid
}

Title: Refund of the appraisal expense and position of consumers who had already obtained a final judgment.

Resumen: A lo largo de este trabajo analizaremos la STS Pleno, núm. 35/2021, de 27-1-2021 que, por primera vez, se pronuncia respecto a la preceptiva restitución del gasto de tasación tras la declaración de nulidad de la cláusula de gastos de formalización del préstamo hipotecario, asumiendo así la doctrina fijada por la STJUE de 16-7-2020. Asimismo, estudiaremos la oportunidad de este criterio mediante el examen de la normativa relativa a la tasación y de las distintas posturas doctrinales al respecto. Finalmente, exploraremos las distintas posibilidades a disposición de los consumidores que ya hubieran obtenido una sentencia firme que declarara la nulidad de su cláusula de gastos en relación con los efectos de la cosa juzgada material y la

\footnotetext{
* Trabajo realizado en el marco del Proyecto de Investigación PGC2018-098683-B-I00, del Ministerio de Ciencia, Innovación y Universidades (MCIU) y la Agencia Estatal de Investigación (AEI) cofinanciado por el Fondo Europeo de Desarrollo Regional (FEDER) titulado "Protección de consumidores y riesgo de exclusión social" y dirigido por Ángel Carrasco Perera y Encarna Cordero Lobato; y en el marco de la Ayuda para la realización de proyectos de investigación científica y transferencia de tecnología, de la Junta de Comunidades de Castilla-La Mancha cofinanciadas por el Fondo Europeo de Desarrollo Regional (FEDER), para el Proyecto titulado "Protección de consumidores y riesgo de exclusión social en Castilla-La Mancha" (PCRECLM) con SBPLY/19/180501/000333, dirigido por Ángel Carrasco Perera y Ana Isabel Mendoza Losana.

** ORCID ID: 0000-0003-2794-9200; LinkedIn: https://www.linkedin.com/in/alicia-ag\%C3\%BCero-ortiz$\underline{71040880 /}$
} 
preclusión de las acciones, e identificaremos el plazo de prescripción de la acción restitutoria.

Palabras clave: cláusula de gastos, tasación, cosa juzgada, preclusión, cláusulas abusivas.

Abstract: Throughout this paper we will analyze the Spanish Supreme Court ruling, of 01-27-2021, which, for the first time, orders the restitution of the appraisal expense after the declaration of nullity of the expenses clause, thus assuming the doctrine established by the CJUE ruling of 16-7-2020. Likewise, we will study the appropriateness of this criterion by examining appraisal regulations and the different doctrinal positions in this regard. Finally, we will explore the different possibilities available to consumers who had already obtained a final judgment declaring the nullity of their expenses clause in relation to the res judicata and preclusion effects, and we will also identify the limitation period of the restitutory action.

Keywords: expenses clause, appraisal, res judicata, preclusion, unfair terms.

SUMARIO: 1. La STS, Pleno, núm. 35/2021, de 27-1-2021 (JUR\2021\31278). 2. La tasación como requisito para iniciar el proceso ejecutivo. 3. La tasación como requisito para movilizar el préstamo hipotecario. 4. La tasación como servicio accesorio cuyo gasto no se atribuía normativamente al prestatario. 5. ¿Qué sucede con los préstamos cuya cláusula de gastos hubiera sido declarado nula pero no se hubiera condenado a restituir el gasto de tasación? 6. Prescripción de la acción restitutoria. 7. Bibliografía.

\section{La STS, Pleno, núm. 35/2021, de 27-1-2021 (JUR \2021 \31278)}

En noviembre de 2014 un consumidor contrató con Liberbank un préstamo hipotecario que incluía una cláusula de gastos por la que la entidad le repercutía todos los gastos de constitución de dicho préstamo. En cumplimiento de esta cláusula, el consumidor abonó $609,19 €$ de gastos notariales; $226,56 €$ de gastos por la inscripción registral; $1953,60 €$ por el impuesto de actos jurídicos documentados; $296,53 €$ por la tasación del inmueble; y $508,20 €$ por gastos de gestoría (un total de $3594,03 €)$.

Con posterioridad, el prestatario interpuso una demanda contra Liberbank instando la declaración de nulidad de la cláusula de gastos, así como la consecuente restitución de todas las partidas abonadas en su virtud. La demanda fue estimada íntegramente por sentencia de 14-7-2017 del JPI n. ${ }^{\circ} 4$ de Cáceres. Liberbank recurrió en apelación la sentencia, recurso que fue desestimado por la SAP de Cáceres, Sec. 1a, de 26-12018 (JUR 2018\68044).

Frente a dicha sentencia, Liberbank interpuso un recurso de casación ante el TS en base a tres motivos, si bien el TS solo enjuició el primero de ellos pues, siendo estimado parcialmente, consideró innecesario evaluar el resto. En concreto, el primer motivo de casación denunciaba la infracción del art. 83 TRLGDCU en relación con el 
art. 1303 CC y la jurisprudencia según la cual, tras la declaración de nulidad de una cláusula de gastos contenida en la escritura de préstamo hipotecario, procedía realizar un examen individualizado de sus concretos efectos a fin de determinar en cada caso la obligación de restitución inherente a dicha declaración de nulidad. De este modo, la demandada pretendía reducir la condena restitutoria de suerte que no alcanzara a todos los gastos satisfechos por el demandante.

Por su parte, como decimos, el TS estimó parcialmente el recurso de casación de Liberbank liberando a la demandada de restituir el importe del impuesto sobre los actos jurídicos documentados y reduciendo el importe a restituir en concepto de gastos de notaría al $50 \%$ de los mismos. Con todo, lo relevante de la sentencia es que no eximió a la demandada de restituir el gasto de tasación. En favor de ello, el TS argumentó que:

10) La tasación no constituye, propiamente, un requisito de validez de la hipoteca, si bien el art. 682.2.10 LEC requiere para la ejecución judicial directa de la hipoteca, entre otros requisitos: «[q]ue en la escritura de constitución de la hipoteca se determine el precio en que los interesados tasan la finca o bien hipotecado, para que sirva de tipo en la subasta, que no podrá ser inferior, en ningún caso, al 75 por cien ${ }^{1}$ del valor señalado en la tasación que, en su caso, se hubiere realizado en virtud de lo previsto en la Ley 2/1981, de 25 de marzo, de Regulación del Mercado Hipotecario».

20) La exigencia de la tasación de la finca de conformidad con la Ley de Mercado Hipotecario es un requisito previo para la emisión de valores garantizados: así se desprende del art. 7 de la Ley, cuyo apartado 1 dispone lo siguiente: «[p]ara que un crédito hipotecario pueda ser movilizado mediante la emisión de los títulos regulados en esta Ley, los bienes hipotecados deberán haber sido tasados por los servicios de tasación de las Entidades a que se refiere el artículo segundo, o bien por otros servicios de tasación que cumplan los requisitos que reglamentariamente se establecerán».

30) Ni el $R D$ 775/1997, de 30 de mayo, sobre régimen jurídico de homologación de los servicios y sociedades de tasación, ni la Orden ECO/805/2003, de 27 de marzo, sobre normas de valoración de bienes inmuebles, contienen disposición normativa alguna sobre quién debe hacerse cargo del coste de la tasación.

Por consiguiente, concluyó que "de acuerdo con la STJUE de 16-7-2020, ante la falta de una norma nacional aplicable en defecto de pacto que impusiera al prestatario el pago de la totalidad o de una parte de esos gastos, no cabía negar al consumidor la

\footnotetext{
1 Límite introducido por la Ley $1 / 2013$, de 14 de mayo, de medidas para reforzar la protección a los deudores hipotecarios, reestructuración de deuda y alquiler social.
} 
devolución de las cantidades abonadas en virtud de la cláusula que se ha declarado abusiva", lo que nos parece plenamente acertado ${ }^{2}$. Como puede observarse, el TS llegó a la misma conclusión que la alcanzada en relación con los gastos de gestoría con posterioridad a la STJUE $16-7-2020^{3}$, en sus SSTS de 26-10-2020 (RJ $2020 \backslash 4140)^{4}$-en la que por primera vez revocó su criterio previo ${ }^{5}$, según el cual solo procedería restituir el 50\% de este gasto6-; de 17-11-2020 (RJ 2020\4605); de 2311-2020 (RJ 2020\4692); así como en la sentencia objeto de comentario.

No obstante lo anterior, el TS matizó que ello solo resultará de aplicación a los préstamos formalizados antes de la entrada en vigor de la Ley 5/2019, de 15 de

\footnotetext{
${ }^{2}$ Como venimos opinando de antiguo: AGÜERO ORTIZ, A.: "Efectos y Alcance de la nulidad de las cláusulas de gastos en préstamos hipotecarios con consumidores. Especial referencia al IAJD y los gastos de tasación", Revista Doctrinal Aranzadi Civil-Mercantil, n. 2, 2017; "Nulidad de la cláusula de gastos en préstamos hipotecarios: no son sólo abusivos los gastos comprendidos en la STS de 23 de diciembre de 2015 (gastos, efectos y plazos)", Centro de Estudios de Consumo (CESCO), enero 2017, disponible en: http://centrodeestudiosdeconsumo.com/images/gastos.pdf; "Cláusula de gastos en la STJUE de 16.7.2020: ¿más gastos restituibles; extensión del plazo para instar la restitución y condena en costas si la cláusula se declara abusiva?", Centro de Estudios de Consumo (CESCO), julio 2020, disponible en: http://centrodeestudiosdeconsumo.com/images/Clausula de gastos en la STJUE de 16.7.2020.pdf; "STJUE de 16 de julio de 2020: procede restituir íntegramente los gastos de formalización del préstamo hipotecario y declarar la abusividad de la comisión de apertura", Revista Jurídica sobre Consumidores y
} Usuarios, vLex, núm. especial, septiembre 2020.

${ }^{3}$ ECLI:EU:C:2020:578.

${ }^{4} \mathrm{Vid}$. al respecto: MARÍN LÓPEZ, M. J.: "El prestatario tiene derecho a recuperar íntegramente los gastos de gestoría tras la nulidad de la cláusula de gastos del préstamo hipotecario. Comentario a la STS 26 de octubre de 2020", Centro de Estudios de Consumo (CESCO), noviembre 2020, disponible en: http://centrodeestudiosdeconsumo.com/images/El prestatario tiene derecho a recuperar integrament e los gastos de gestoria tras la nulidad de la clausula de gastos del prestamo hipotecario.pdf (última consulta: 10-2-2021).

${ }^{5}$ De suerte que, no es cierto que "[e]l esperado pronunciamiento del TJUE sobre los efectos que conlleva la declaración de nulidad de la cláusula de gastos de nada ha servido en cuanto a la protección de los consumidores, pues según el Tribunal Supremo nada ha cambiado tras la STJUE de 16 de julio de 2020", MARTÍNEZ GÓMEZ, S.: "Las expectativas de recuperación del 100\% de los gastos Hipotecarios, generadas por la STJUE 16.07.2020 y la SAP de las Palmas de 21.07.2020, han caído en saco roto tras ratificar el TS su doctrina sobre el reparto de los gastos", Centro de Estudios de Consumo (CESCO), septiembre 2020, disponible en:

http://centrodeestudiosdeconsumo.com/images/Las expectativas de recuperaci\%C3\%B3n del 100 de los gastos hipotecarios han caido en saco roto tras ratificar el TS su doctrina sobre el reparto de los gastos.pdf (última consulta: 10-2-2020). Aunque debemos resaltar que al tiempo de escribirse dichas líneas aún no se había producido la rectificación por parte del TS.

6 "Respecto de los gastos de gestoría por la tramitación de la escritura ante el Registro de la Propiedad y la oficina liquidadora del impuesto, en la sentencia 49/2019, de 23 de enero (RJ 2019, 92), entendimos que como «cuando se haya recurrido a los servicios de un gestor, las gestiones se realizan en interés o beneficio de ambas partes, el gasto generado por este concepto deberá ser sufragado por mitad». Este criterio no se acomoda bien a doctrina contenida en la STJUE de 16 de julio de 2020 (TJCE 2020, 104), porque con anterioridad a la Ley 5/2019, de 15 de marzo (RCL 2019, 438), de Contratos de Crédito Inmobiliario, no existía ninguna previsión normativa sobre cómo debían abonarse esos gastos de gestoría. En esa situación, ante la falta de una norma nacional aplicable en defecto de pacto que impusiera al prestatario el pago de la totalidad o de una parte de esos gastos, no cabía negar al consumidor la devolución de las cantidades abonadas en virtud de la cláusula que se ha declarado abusiva". 
marzo, reguladora de los contratos de crédito inmobiliario ("LCCI") -el 16-6-2019-, dado que su artículo 14.e) i) sí impone al prestatario la asunción del gasto de tasación.

Nos parece curioso que el TS precediera su conclusión, a saber, que dado que no existía norma que atribuyera el gasto de tasación al prestatario debía procederse a la restitución de su coste, de determinadas valoraciones de la normativa relativa a la tasación como si se pretendiese dejar patente que esta constituye un pseudorequisito para la concesión o constitución del préstamo hipotecario (aunque puede que la pretensión fuera meramente expositiva). Así, se afirma que no constituye "propiamente" un requisito constitutivo "si bien" es necesario para poder ejecutar; o "es un requisito previo para la emisión de valores garantizados" debe notarse que ninguno de dichos requisitos es requerido para la constitución del préstamo hipotecario (cfr. arts. 1857 y 1875 CC; y art. $145 \mathrm{LH})^{8}$ ni operan en interés del prestatario (como si ello, en ausencia de la STJUE 16-7-2020, pudiera justificar en modo alguno su repercusión al mismo, tal y como argumentaba el TS en relación con el gasto de gestoría antes de la mencionada sentencia europea). En nuestro criterio, tales normativas conducirían a concluir lo contrario, esto es, que el gasto de tasación o la realización de la tasación no opera en interés del prestatario, sino del prestamista.

\section{La tasación como requisito para iniciar el proceso ejecutivo}

Como apunta el TS, la tasación del inmueble constituye un requisito para acceder al procedimiento de ejecución hipotecaria. Así el art. 682.2.1.0 de la LEC exige para la aplicación de las disposiciones del procedimiento ejecutivo hipotecario que "en la escritura de constitución de la hipoteca se determine el precio en que los interesados tasan la finca o bien hipotecado, para que sirva de tipo en la subasta, que no podrá ser inferior, en ningún caso, al 75 por cien del valor señalado en la tasación que, en su caso, se hubiere realizado en virtud de lo previsto en la Ley 2/1981, de 25 de

\footnotetext{
7 Estas dos exigencias legales, para determinadas finalidades -no como requisito constitutivo del préstamo hipotecario-, conducen a GÓMEZ POMAR y ARTIGOT GOLOBARDES a calificar el coste de tasación como "exógeno en su naturaleza, pues se impone legalmente a las partes". GÓMEZ POMAR, F.; ARTIGOT GOLOBARDES, M.: "Costes, precios y excedente contractual en el control de la contratación de consumo, especialmente la hipotecaria", ADC, tomo LXXIII, 2020, fasc. I, pp, p. 77.

${ }^{8}$ Art. 1857 CC: "[s]on requisitos esenciales de los contratos de prenda e hipoteca: $1 .^{\circ}$ Que se constituya para asegurar el cumplimiento de una obligación principal; $2.0^{\circ}$ Que la cosa pignorada o hipotecada pertenezca en propiedad al que la empeña o hipoteca; 3. ${ }^{\circ}$ Que las personas que constituyan la prenda o hipoteca tengan la libre disposición de sus bienes o, en caso de no tenerla, se hallen legalmente autorizadas al efecto (...)". Art. 1875 CC: "[a]demás de los requisitos exigidos en el artículo 1.857, es indispensable, para que la hipoteca quede válidamente constituida, que el documento en que se constituya sea inscrito en el Registro de la Propiedad. Las personas a cuyo favor establece hipoteca la ley, no tienen otro derecho que el de exigir el otorgamiento e inscripción del documento en que haya de formalizarse la hipoteca (...)". Art. 145 LH: "[p]ara que las hipotecas voluntarias queden válidamente establecidas, se requiere: Primero. Que se hayan constituido en escritura pública. Segundo. Que la escritura se haya inscrito en el Registro de la Propiedad".
} 
marzo, de Regulación del Mercado Hipotecario"9. Igualmente, el art. 129.2.a) LH en su redacción dada por la disposición final primera de la LCCI dispone, en relación con el procedimiento de ejecución extrajudicial que "[e]l valor en que los interesados tasen la finca para que sirva de tipo en la subasta no podrá ser distinto del que, en su caso, se haya fijado para el procedimiento de ejecución judicial directa, ni podrá en ningún caso ser inferior al valor señalado en la tasación que, en su caso, se hubiere realizado en virtud de lo previsto en la Ley 2/1981, de 25 de marzo, de regulación del mercado hipotecario"10. En este sentido, el art. 234.1 del Reglamento Hipotecario exige, para la tramitación del procedimiento de ejecución extrajudicial, que en la escritura de constitución de la hipoteca se incluya "el valor en que los interesados tasan la finca para que sirva de tipo en la subasta. Dicho valor no podrá ser distinto del que, en su caso, se haya fijado para el procedimiento judicial sumario".

Por lo tanto, una de las finalidades de la tasación es permitir al acreedor acceder al procedimiento de ejecución judicial y extrajudicial, así como determinar el tipo de subasta en los procedimientos ejecutivos judiciales y extrajudiciales. En consecuencia, lejos de efectuarse en beneficio o interés del prestatario, la tasación se realiza en beneficio de la entidad prestamista, en tanto que constituye un requisito que la ley procesal impone para que el acreedor pueda acceder al procedimiento de ejecución hipotecaria judicial (art. 682 LEC). Siendo así que la única parte interesada en poder acceder al procedimiento ejecutivo es, simple y llanamente, el acreedor garantizado. En palabras de GÁMEZ GUMERSINDO, el gasto de tasación es un gasto "que nuevamente debería ser asumido por la entidad bancaria, por cuanto constituye un instrumento de valoración del inmueble que garantiza la devolución del préstamo, y que, de conformidad con el art. 682.2 de la LEC, constituye requisito preceptivo para el inicio de los procedimientos de ejecución de la garantía hipotecaria, puesto que configura el tipo de subasta, preceptuando que este no podrá ser inferior al $75 \%$ del valor otorgado en el informe de tasación"11.

Con todo, SANJUÁN manifiesta de contrario que "a partir de 2013 y con la entrada en vigor de dicha norma [Ley 1/2013] y también por la modificación de la Ley 19/2015 de 13 de julio y considerando la interpretación de la DGRN, resultará que para que puedan ser inscritas dichas cláusulas de ejecución especial y extrajudicial es necesario que conste dicha tasación; y que la misma ya no solo obedece a los criterios anteriores de tasación referidos a la titulación que podrían hacer las

\footnotetext{
${ }^{9}$ Redacción dada por la Ley 1/2013, originalmente el art. 682.2. 1. ${ }^{\circ}$ LEC establecía que, el procedimiento de ejecución hipotecaria podrá seguirse siempre que ( $y$, entre otras cosas) "en la escritura de constitución de la hipoteca se determine el precio en que los interesados tasan la finca o bien hipotecado, para que sirva de tipo en la subasta".

${ }^{10}$ En la redacción dada por la Ley 1/2013 se permitía que fuera inferior al 75\% del valor de tasación: "[e]l valor en que los interesados tasen la finca para que sirva de tipo en la subasta no podrá ser distinto del que, en su caso, se haya fijado para el procedimiento de ejecución judicial directa, ni podrá en ningún caso ser inferior al 75 por cien del valor señalado en la tasación realizada conforme a lo previsto en la Ley 2/1981, de 25 de marzo, de Regulación del Mercado Hipotecario".

11 GÁMEZ GUMERSINDO, C.: "Préstamos hipotecarios. Abusividad de la cláusula relativa a los gastos de formalizacion de la hipoteca, imputados de forma genérica al consumidor", Revista de Derecho, Empresa y Sociedad (REDS), n.o 10, 2017.
} 
entidades financieras sino también a la protección del consumidor en cuanto a los porcentajes de adjudicación. Antes la tasación partía de considerar porcentajes que nada tenían que ver con el consumidor sino con los -valga la expresión- los porcentajes que debía cumplir la entidad financiera a efectos de titulización. El efecto que se ha producido entonces es doble: por un lado, la existencia de la tasación por entidad homologada beneficiará al consumidor en tanto a seguridad jurídica pero su determinación (es decir el avalúo) no obedecía a criterios de protección sino a criterios de inversión o desinversión para la entidad. Tras la regulación posterior se beneficiará de la limitación de porcentaje, pero sobre una base que se constituyó teniendo en cuenta otros intereses. Por otro lado, que con esa tasación que se realizaba la entidad financiera (antes y ahora también) garantiza el riesgo a efectos de préstamo de tal forma que (por ello la garantía) la finca hipotecada cubriría el importe porcentual concreto del préstamo que se hubiera otorgado con cierta seguridad en su otorgamiento"12.

Sin embargo, comparto con FERNÁNDEZ SEIJO que ni el debate sobre a quién beneficia la tasación es útil (pues el hecho es que la normativa no imponía el gasto al consumidor, por lo que, todo lo demás "da ya igual"); ni que en realidad y, a pesar de lo apuntado por SANJUÁN, la tasación se realice en beneficio del consumidor. En sus propios términos: "finalmente, se ha optado por la opinión mayoritaria de entender que la tasación beneficia al prestatario, ya que esa valoración le permite determinar el límite del préstamo. Esta afirmación no es del todo correcta dado que la hipoteca no deja de ser una garantía ofrecida para obtener un préstamo, garantía que, en condiciones normales, no tendrá que ejecutarse puesto que el prestatario confía en sus recursos y en su capacidad de pago para no perder la vivienda"13. Igualmente, BALLUGERA GÓMEZ: "el lobby bancario ha conseguido poner en la LEC sus ambiciones y se puede adjudicar la finca no por el valor que acordó sino por un porcentaje menor o incluso por el importe de la deuda. Nuestra doctrina civilista se entretiene en discusiones bizantinas y, lejos de denunciar este ataque al mercado y a la autonomía de la voluntad, se dedica a sostener que un porcentaje sobre el valor de tasación sigue haciendo de la tasación un elemento beneficioso para el deudor y continua altercando sobre si la adjudicación, tras la subasta fracasada, puede hacerse no ya por un porcentaje sino por el importe menor de la deuda aunque sea ínfimo en relación con el valor del inmueble dado en garantía"14.

\footnotetext{
12 SANJUÁN, E.: "Deben restituirse los gastos de tasación como efecto derivado de la nulidad de la cláusula gastos? De ser así, la restitución ha de total o parcial", Revista de consumo y empresa, n.o 10, 2019.

${ }^{13}$ FERNÁNDEZ SEIJO, J. Ma: "Deben restituirse los gastos de tasación como efecto derivado de la nulidad de la cláusula gastos? De ser así, la restitución ha de total o parcial", Revista de consumo y empresa, n. ${ }^{\circ}$ 10, 2019. También ÁLVAREZ OLALLA: "si bien permite al consumidor obtener un determinado importe del préstamo, en unas determinadas condiciones, también habilita a la entidad para titulizar la hipoteca y valerse, en caso de incumplimiento del consumidor, de los procedimientos especiales de ejecución". ÁLVAREZ OLALLA, Ma. P.: "Cláusula suelo, interés moratorio, vencimiento anticipado e imposición de gastos a consumidor en el préstamo hipotecario", La Ley mercantil, n.o 35, 2017.

${ }^{14}$ BALLUGERA GÓMEZ, C.: "Distribución de gastos en la hipoteca y comisión de apertura. Comentario y resumen de la STJUE de 16 julio 2020", Revista de Derecho vLex, n. 195, 2020. Lo que también denuncia en "Cinco sentencias para moderar el abuso en los gastos hipotecarios. Breve comentario de urgencia de
} 
Especialmente clarificador es el razonamiento de CASTILLO MARTÍNEZ, a saber, "[c]iertamente, sin venir a determinar como criterio exclusivo el importe del préstamo concedido, el resultado de la tasación del inmueble es tenido en cuenta por la entidad financiera a los efectos de concretar las condiciones económicas de la oferta crediticia (...). No obstante lo cual, el fin de la tasación no se agota con este propósito que ni siquiera es el más relevante de sus objetivos (...). En efecto, tal y como ya quedó señalado, la tasación del inmueble va a permitir al acreedor hipotecario el ejercicio de la acción ejecutiva -judicial y extrajudicial- del título no judicial en que la inscrita escritura de constitución de la hipoteca consiste (art. $517.2 .4^{\circ}$ de la LECiv) (...) por lo que cabe concluir que la entidad prestamista tiene un evidente interés en que se realice la tasación del inmueble que va a servir de garantía para su crédito"15.

\section{La tasación como requisito para movilizar el préstamo hipotecario}

La segunda finalidad de las tasaciones es permitir que el préstamo hipotecario sea elegible para su movilización ${ }^{16}$, esto es, permitir a las entidades de crédito emitir bonos hipotecarios, cédulas hipotecarias, etc ${ }^{17}$. Así, dispone el art. $7.1 \mathrm{LMH}$ que "[p]ara que un crédito hipotecario pueda ser movilizado mediante la emisión de los títulos regulados en esta Ley, los bienes hipotecados deberán haber sido tasados". Nos adherimos a la advertencia efectuada por MARÍN NARROS: "[n]ótese que la referida norma nunca habla de obligaciones de los prestatarios, sino de los prestamistas y de las sociedades de tasación"18.

Por su parte, el art. 8.1 del Real Decreto 716/2009, de 24 de abril, por el que se desarrollan determinados aspectos de la Ley 2/1981, de 25 de marzo, de regulación del mercado hipotecario y otras normas del sistema hipotecario y financiero, deja claro que la finalidad de la tasación no es proteger al deudor hipotecario, sino al

\footnotetext{
la STS 46/2019, de 23 enero", Revista de Derecho vLex, n.o 177, 2019, al criticar que se permita "la adjudicación al acreedor, no por el valor de tasación para subasta pactado de la finca e inscrito en la hipoteca, sino por un porcentaje de esa tasación".

15 CASTILLO MARTÍNEZ, C. C.: "Sobre la nulidad de la cláusula de gastos en los préstamos hipotecarios con consumidores", Actualidad civil, n. 0 9, 2017.

${ }^{16}$ RIBÓN SEISDEDOS insiste en que la tasación "es imprescindible para la emisión de bonos hipotecarios, de ser objeto de participaciones hipotecarias o de servir para el cálculo del límite de emisión de las cédulas hipotecarias". RIBÓN SEISDEDOS, E.: "Cláusula Suelo y reclamación de gastos hipotecarios. Acciones para su eliminación y devolución de cantidades indebidamente percibidas", Editorial Sepín.

${ }^{17}$ Lo que ha promovido la realización de las tasaciones sobrevaloradas, con la finalidad de poder movilizar los préstamos hipotecarios (perdiendo el riesgo de insolvencia del prestatario que se transmite a los adquirentes de los títulos hipotecario) mostrándolos al mercado como menos arriesgados al estar respaldados por una hipoteca sobre un inmueble de valor significativamente superior al valor del préstamo. 18 MARÍN NARROS, H. D.: "Nulidad de la condición general de asunción de gastos de los préstamos hipotecarios y consecuente distribución y devolución de los mismos (notaría y registro de constitución y cancelación de la hipoteca, tasación y gestoría) conforme a las SSTS de 23 de diciembre de 2015, de 23 de enero de 2019 y resto de jurisprudencia del Tribunal Supremo y de las Audiencias Provinciales", Revista Crítica de Derecho Inmobiliario, n. ${ }^{0} 773,2019$, p. 1668.
} 
prestamista e inversores en títulos hipotecarios (favoreciendo así la comercialización por parte de las entidades prestamistas, lo que les permite liberarse del riesgo de insolvencia del deudor). En particular, estipula que "[I]os bienes inmuebles por naturaleza sobre los que recaiga la hipoteca deberán haber sido tasados con anterioridad a la emisión de títulos por los servicios de tasación de la entidad financiera prestamista o de entidades homologadas, con arreglo a lo que dispone este real decreto. Dicha tasación tiene por objeto estimar de forma adecuada el precio que pueden alcanzar aquellos bienes de manera que su valor se constituya en garantía última de las entidades financieras y de los ahorradores que participen en el mercado".

Más claro, si cabe, lo expresa la Exposición de Motivos de la Orden ECO/805/2003, de 27 de marzo, sobre normas de valoración de bienes inmuebles y de determinados derechos para ciertas finalidades financieras: "[l]a presente Orden establece normas para el cálculo del valor de tasación de bienes inmuebles y de determinados derechos reales para las finalidades contempladas en su ámbito de aplicación, (...) con el objetivo último de proteger más y mejor los intereses de terceros en su condición de inversores o asegurados". Asimismo, los arts. 1 y 2 de Orden ECO/805/2003 determinan, de nuevo, claramente que la tasación constituye un requisito para titulizar el préstamo, no para concederlo.

Lo expuesto nos conduce a considerar, de nuevo, que la tasación se realiza en interés de la entidad prestamista, pues tiene como finalidad que el acreedor pueda movilizar el préstamo hipotecario y, así, emitir bonos hipotecarios, participaciones hipotecarias o cédulas hipotecarias, liberándose del riesgo de insolvencia del deudor que resulta trasladado a los inversores. Así pues, como señala MARÍn NARROS "la tasación por regla general tiene varios beneficios directos para la entidad financiera como servir de tipo para la subasta de una posible ejecución de la garantía por parte del prestamista o el cumplimiento de la Ley 2/1981, de 25 de marzo, de regulación del Mercado Hipotecario para emitir los títulos necesarios para su financiación" ${ }^{19}$. También SANJUÁN: "[e]n relación a ello la Ley Hipotecaria no exige que se realice una tasación del inmueble que se va a hipotecar salvo que las mismas se vayan a titulizar (art. 7 de la Ley 2/1981 de RMH) y ello irá siempre a favor de la entidad financiera que es quien mediante dicha titulización no solo hará negocio sino que limitará el riesgo"20.

Criterio idénticamente compartido por CASTILLO MARTÍNEZ: "la tasación va a posibilitar que el crédito hipotecario pueda ser catalogado de elegible a los efectos de su movilización, favoreciendo de este modo a la entidad crediticia que va a poder emitir cédulas, bonos y participaciones hipotecarias, en definitiva valores negociables cuya mercantilización va a reportar beneficios no precisamente al consumidor prestatario sino a la entidad financiera garantizada. Sin duda, la ponderación de las ventajas de la tasación del inmueble ofrecido en garantía brinda como resultado la realidad de una parte contratante destacadamente beneficiada por su concurrencia

19 MARÍN NARROS, H. D.: "Nulidad de la condición general de asunción...", op. cit., pp. 1670-1671.

20 SANJUÁN, E.: "Deben restituirse los gastos de tasación...", op. cit. 
que es la entidad prestamista (...). Por ello considero que la estipulación mediante la que de manera sistemática se impongan al consumidor los gastos generados por la tasación del inmueble debe ser tachada de abusiva y, por ende, ser declarada nula"21.

\section{La tasación como servicio accesorio cuyo gasto no se atribuía normativamente al prestatario}

Adicionalmente, debe resaltarse que tanto el art. 15 de la Ley 2/2009 como el art. 4 de la ya derogada Orden de 5 de mayo de 1994, califican este servicio como un servicio accesorio, cuyo traslado al consumidor puede efectuarse previa información expresa contenida en dichos preceptos $y$, en todo caso, sin perjuicio de la aplicación del control de abusividad para el caso de que esta traslación no hubiera sido negociada individualmente (arts. 1.3 y 4.1 .III, respectivamente).

Por su parte, el art. 40 RD-L 6/2000, de 23 de junio, de Medidas Urgentes de Intensificación de la Competencia en Mercados de Bienes y Servicios, no imponía el gasto de tasación al prestatario ${ }^{22}$, sino que se limitaba a imponer a las entidades financieras que incluyeran en los folletos informativos previos a la formalización de los préstamos garantizados con hipoteca inmobiliaria "el derecho que asiste al prestatario para designar, de mutuo acuerdo con la parte prestamista, la persona o entidad que vaya a llevar a cabo la tasación del inmueble objeto de la hipoteca". Precepto, este último, que había sido utilizado como justificación de la atribución del gasto de tasación y gestoría al prestatario por algunos jueces y tribunales, aunque como bien expone BALLUGERA GÓMEZ: "[c]on esta indicación se deja caer que los gastos de tasación son a cargo de la persona consumidora, olvidando que la tasación no era obligatoria para el deudor al tiempo de la celebración de los contratos enjuiciados y que solo procedía de mutuo acuerdo"23.

Por su parte, la Orden EHA/2899/2011, de 28 de octubre, de transparencia y protección del cliente de servicios bancarios, establece que la FIPRE deberá informar sobre "si resulta exigible la tasación del inmueble y a cargo de quién serán los gastos de la misma" (Anexo I, Parte B, Sección 4), lo que nuevamente denota su carácter no esencial, así como la ausencia de atribución normativa del gasto al prestatario.

No obstante, tras la modificación de la Orden $2899 / 2011$ por la Orden ECE/482/2019, de 26 de abril, por la que se modifican la Orden EHA/1718/2010, de 11 de junio, de regulación y control de la publicidad de los servicios y productos bancarios, y la Orden $\mathrm{EHA} / 2899 / 2011$, de 28 de octubre, de transparencia y protección del cliente de servicios bancarios, que desarrolla la LCCI (en vigor desde el 16-6-2019), sí se ordena que la ficha de advertencias estandarizadas informe de que el gasto de

\footnotetext{
${ }^{21}$ CASTILLO MARTÍNEZ, C. C.: "Sobre la nulidad de la cláusula de gastos...", op. cit.

22 MATE SATUÉ, L. C.: "Transparencia y abusividad de la cláusula de gastos en los préstamos para adquisición de vivienda", Revista Crítica de Derecho Inmobiliario, n.o 772, 2019, p. 931.

${ }^{23}$ BALLUGERA GÓMEZ, C.: "Distribución de gastos en la hipoteca...", op. cit.
} 
tasación corresponde al prestatario, en coherencia con la imposición de este gasto al prestatario prevista en el art. 14 LCCI.

\section{5. ¿Qué sucede con los préstamos cuya cláusula de gastos hubiera sido declarado nula pero no se hubiera condenado a restituir el gasto de tasación?}

Todo dependerá de las acciones que se ejercitaron en la demanda, así como de lo pedido específicamente en aquella. En concreto, dependerá de si se ejercitó exclusivamente una acción declarativa de nulidad, en cuyo caso cabrá un ejercicio ulterior de la acción restitutoria. A mayor abundamiento, de haberse ejercitado conjuntamente la acción de nulidad con la acción resarcitoria, la cuestión dependerá de los gastos cuya restitución se instó.

De esta suerte, si ejercitada la acción restitutoria se hubiera solicitado la restitución de "todos los gastos" o, específicamente, del gasto de tasación, habiendo recaído sentencia firme que desestimara esta pretensión o que la estimara parcialmente, existirá cosa juzgada material ${ }^{24}$, de forma que el consumidor no podrá instar, de nuevo, la restitución del gasto de tasación.

Por el contrario, si tan solo se hubiera ejercitado la acción declarativa de nulidad o, habiéndose solicitado la restitución, esta petición se hubiera restringido a la restitución de determinados gastos sin incluir el gasto de tasación, entonces cabrá instar la restitución del gasto de tasación, siempre que la acción restitutoria no hubiera prescrito, a lo que nos referiremos infra.

Esto es así ya que, de conformidad con el art. 222.1 LEC "[I]a cosa juzgada de las sentencias firmes, sean estimatorias o desestimatorias, excluirá, conforme a la ley, un ulterior proceso cuyo objeto sea idéntico al del proceso en que aquélla se produjo". Asimismo, el art. 222.2 LEC detalla que "[I] a cosa juzgada alcanza a las pretensiones de la demanda y de la reconvención (...). Se considerarán hechos nuevos y distintos, en relación con el fundamento de las referidas pretensiones, los posteriores a la completa preclusión de los actos de alegación en el proceso en que aquéllas se formularen".

Por su parte, el art. 400 LEC establece la preclusión de la alegación de hechos y fundamentos jurídicos (no de pretensiones no ejercitadas) como sigue: "1. Cuando lo que se pida en la demanda pueda fundarse en diferentes hechos o en distintos fundamentos o títulos jurídicos, habrán de aducirse en ella cuantos resulten

\footnotetext{
${ }^{24}$ CARRASCO PERERA, Á.: [en relación con las cláusulas suelo] "cuando haya existido ya una sentencia firme en acción individual con condena a devolución no retroactiva, prevalecerá la cosa juzgada". CARRASCO PERERA, Á.: "Retroactividad de la nulidad, procedimiento extrajudicial de reembolso de intereses por cláusulas suelo y el problema de la cosa juzgada", Centro de Estudios de Consumo (CESCO), enero 2017, disponible en:

http://www.centrodeestudiosdeconsumo.com/images/CONDICIONES GENERALES DE LA CONTRATACI ON/Clausula-suelo-y-cosa-juzgada.pdf (última consulta: 10-2-2021).
} 
conocidos o puedan invocarse al tiempo de interponerla, sin que sea admisible reservar su alegación para un proceso ulterior (...). 2. De conformidad con lo dispuesto en al apartado anterior, a efectos de litispendencia y de cosa juzgada, los hechos y los fundamentos jurídicos aducidos en un litigio se considerarán los mismos que los alegados en otro juicio anterior si hubiesen podido alegarse en este". En relación con ello, el TS declaró en su sentencia de 21-7-2016 (RJ 2016\3212) que "la ley establece una verdadera preclusión en la alegación de hechos y fundamentos jurídicos que apoyan la acción, pero en forma alguna determina el objeto de la pretensión sobre la que ha de decidir exclusivamente el demandante. Extiende por ello la cosa juzgada material a todas las posibles «causas de pedir» con que pudiera contar el demandante en el momento de formular su demanda pero únicamente respecto de la concreta pretensión que formula"25.

Como explica RODRÍGUEZ ACHÚTEGUI, cuyo criterio compartimos, "[d]e tal regulación se desprende que las consecuencias de no alegar todos los títulos o hechos afectan solo a la pretensión deducida en la demanda, pero no a las que no se plantearon. La carga para el actor es no escamotear los títulos o razones que justifican su pretensión, ni los hechos que pueda haber esgrimido en su favor (...) porque la ley deja bien claro que la cosa juzgada material se circunscribe a las pretensiones de demanda y reconvención (art. 222.2 LEC) y a lo que se pida en la demanda (art. 400.1 LEC), es decir, a la petición a que alude el art. 399.5 LEC". Continuando el autor, en relación con las cláusulas suelo ${ }^{26}$, "[d]e esta forma quien solicitó una simple condena declarativa, la nulidad de la cláusula suelo, pero no pidió la restitución de las cantidades, no puede verse afectado por la santidad de la cosa juzgada. Ni tampoco quien pidió la nulidad y la condena a restituir desde la publicación de la STS 9 de mayo de 2013, puesto que no incluyó en la solicitud de su demanda cantidades anteriores, y por tanto, se trata de una cuestión imprejuzgada. En ambos casos entiendo que no operan las consecuencias de la institución de la cosa juzgada porque no puede haberla respecto de peticiones no articuladas, las únicas que pueden ser enjuiciadas y resueltas como consecuencia del principio dispositivo que rige el proceso civil"27.

\footnotetext{
${ }^{25}$ Sin que sea óbice a ello la STS de 13-11-2018 (RJ 2018\5219) en la que se aprecia existencia de cosa juzgada en un supuesto de hecho en el que el consumidor ejercitó una acción de resolución contractual de un contrato de compraventa de vivienda, siendo posteriormente demandado, reconviniendo frente a ello e instando la declaración de abusividad de determinadas cláusulas del contrato. En concreto, porque la sentencia reconoce expresamente que "ya que en el litigio anterior entre las mismas partes tanto la juez de primera instancia como el tribunal de apelación examinaron el contrato de compraventa «y ninguna nulidad se apreció de oficio, lo que implica un previo control judicial del contrato»".

${ }^{26}$ Puede encontrarse un magnífico análisis de las distintas posturas esgrimidas al respecto, aunque con criterio contrario al aquí sostenido, en MARTÍN FABA, J. Ma.: "La vinculación entre la acción declarativa de nulidad de cláusula suelo y la de restitución de intereses hace que ambas deban ejercitarse conjuntamente", Centro de Estudios de Consumo (CESCO), septiembre de 2017, disponible en: http://centrodeestudiosdeconsumo.com/images/Vinculacion entre accion de nulidad de cl\%C3\%A1us ula suelo y restitucion de intereses.pdf (última consulta: 10-2-2021).

27 RODRÍGUEZ ACHÚTEGUI, E.: "Tras la doctrina del TJUE: ¿sigue siendo santa la cosa juzgada?", Revista Aranzadi Doctrinal, n. ${ }^{0}$ 4, 2017.
} 


\section{Prescripción de la acción restitutoria}

En relación con la prescripción de la acción de restitución, hemos de recordar que la STJUE 16-7-202028 declaró que es válido vincular el ejercicio de la acción restitutoria a un plazo de prescripción, como el de cinco años previsto en el art. 1964.2 CC, "siempre que ni el momento en que ese plazo comienza a correr ni su duración hagan imposible en la práctica o excesivamente difícil el ejercicio del derecho del consumidor a solicitar tal restitución". En consecuencia, comprendemos que la acción restitutoria relativa a la cláusula de gastos de préstamos concertados antes de la publicación de la STS 23 diciembre de 2015 (lo que tuvo lugar el 21 de enero de 2016), contaban en condiciones ordinarias- con un plazo de prescripción de cinco años desde dicha publicación, es decir, hasta el 21 de enero de 2021. De este modo, se cumpliría el mandato del TJUE, a saber, que el dies a quo del ejercicio de la acción no haga imposible su ejercicio, lo que acaecería si este fuera el día de contratación del préstamo, años antes de conocer que tal cláusula era abusiva.

Ahora bien, el RD 463/2020, de 14 de marzo, que declara el estado de alarma, estableció en su DA $4^{a}$ que "los plazos de prescripción y caducidad de cualesquiera acciones y derechos quedarán suspendidos durante el plazo de vigencia del estado de alarma y, en su caso, de las prórrogas que se adoptaren". Por su parte, el art. 10 del RD 537/2020, de 22 de mayo, determinó que "con efectos desde el 4 de junio de 2020, se alzará la suspensión de los plazos de prescripción y caducidad de derechos y acciones", añadiendo la disposición derogatoria única que "con efectos desde el 4 de junio de 2020, quedan derogadas las disposiciones adicionales segunda y cuarta del Real Decreto 463/2020, de 14 de marzo"29. De modo que el plazo de prescripción quedó suspendido entre el 14 de marzo de marzo 2020 y el 3 de junio 2020 (82 días, art. $5.2 \mathrm{CC})^{30}$. Por consiguiente, la acción restitutoria relativa a la cláusula de gastos de préstamos concertados antes del 21 de enero de 2016 prescribirá el 13 de abril de 2021.

\footnotetext{
${ }^{28}$ ECLI:EU:C:2020:578.

${ }^{29} \mathrm{Vid}$. al respecto, ACHÓN BRUÑÉN, Ma. J.; AGÜERO ORTIZ, A.; DIEGO DIAGO, M. D.; FRAGA MANDIÁN, A.; MARÍN LÓPEZ, M. J.; ORTIZ AGUIRRE, J. M.a; SÁNCHEZ GARCÍA, J. Ma: "Encuesta jurídica. Una vez alzada la suspensión de los plazos sustantivos de prescripción y caducidad ¿se reinician o se reanudan a partir del 4 de junio? ¿Qué fórmula sería la adecuada para calcular el cómputo?", Top Jurídico Consumidores y Usuarios, Editorial Jurídica Sepín, julio 2020, ref. SP/DOCT/106637, URL: https://www.sepin.es/cronus4plus/documento/VerDoc.asp?dist=21\&referencia=SP\%2FDOCT\%2F106637

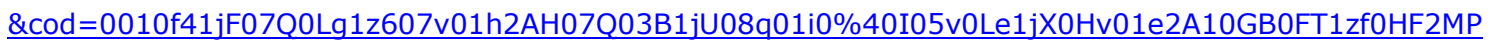
0\%4020H607p0\%24V09P2JK0GE08p1S\%5F1Cm0JP1\%24n1yx0Cf1yF1Cp (última consulta: 21-2-2021).

${ }^{30} \mathrm{Vid}$. Propuesta del CGP] de 20/4/2020: "[I]os plazos de prescripción y caducidad de acciones y derechos suspendidos durante la vigencia del estado de alarma se reanudarán por el período que restase cuando se alce el estado de alarma, aplicando las reglas de cómputo establecidas en el párrafo segundo", esto es, si los plazos estuviesen fijados en días se contarán por días los restantes para el cumplimiento, y si estuvieran "establecidos por meses o años, (...) se adicionarán a partir del día de vencimiento ordinario, computado de fecha a fecha, los días naturales del periodo de interrupción o suspensión" [del 14-3-20203-6-2020; 82 días]. Disponible en: https://www.poderjudicial.es/cgpj/es/Poder-Judicial/En-Portada/ElCGPJ-remite-trece-propuestas-al-Gobierno-para-que-estudie-su-inclusion-en-el-Real-Decreto-ley-demedidas-urgentes-para-la-Administracion-de-Justicia- (última consulta: 10-2-2021).
} 
Por su parte, los prestatarios que hubieren concertado sus préstamos hipotecarios tras la publicación de dicha sentencia (21-1-2016), contarán con un plazo de prescripción de cinco años desde la suscripción del contrato, incrementado en 82 días como consecuencia de la suspensión de los plazos de prescripción estudiada.

Nótese, empero, que cualquier reclamación judicial o extrajudicial interrumpe dicho plazo de prescripción (art. 1973 CC), de suerte que, si el consumidor hubiera presentado o presentara una reclamación al respecto ante el prestamista antes de transcurrir los plazos comentados, el plazo de prescripción habría quedado o quedaría interrumpido, paralizado, desde la interposición de dicha reclamación.

A mayor abundamiento, consideramos que los consumidores que hubieran visto su cláusula de gastos anulada por abusiva, y que reúnan las condiciones expuestas para instar nuevamente la restitución del gasto de tasación, deberían ver satisfecha esta pretensión extrajudicialmente. De lo contrario, la entidad prestamista incurriría en la nueva infracción de consumo introducida en el art. 49.1.i) TRLGDCU por el Real Decreto-ley 37/2020, de 22 de diciembre, a saber: "la no remoción de sus efectos [de los efectos de una cláusula abusiva introducida en el contrato] una vez declarado judicialmente su carácter abusivo o sancionado tal hecho en vía administrativa".

\section{Bibliografía}

ACHÓN BRUÑÉN, Ma. J.; AGÜERO ORTIZ, A.; DIEGO DIAGO, M. D.; FRAGA MANDIÁN, A.; MARÍN LÓPEZ, M. J.; ORTIZ AGUIRRE, J. M.a; SÁNCHEZ GARCÍA, J. Ma: "Encuesta jurídica. Una vez alzada la suspensión de los plazos sustantivos de prescripción y caducidad ¿se reinician o se reanudan a partir del 4 de junio? ¿Qué fórmula sería la adecuada para calcular el cómputo?", Top Jurídico Consumidores y Usuarios, Editorial Jurídica Sepín, julio 2020, ref. SP/DOCT/106637, URL:

https://www.sepin.es/cronus4plus/documento/VerDoc.asp?dist=21\&referencia=SP \%2FDOCT\%2F106637\&cod=0010f41jF07Q0Lg1z607v01h2AH07Q03B1jU08q01i0\% 40I05v0Le1jX0Hv01e2A10GB0FT1zfOHF2MP0\%4020H607p0\%24V09P2JK0GE08p1S \%5F1Cm0JP1\%24n1yx0Cf1yF1Cp

AGÜERO ORTIZ, A.: "Efectos y Alcance de la nulidad de las cláusulas de gastos en préstamos hipotecarios con consumidores. Especial referencia al IAJD y los gastos de tasación", Revista Doctrinal Aranzadi Civil-Mercantil, n. 0 2, 2017.

AGÜERO ORTIZ, A.: "Nulidad de la cláusula de gastos en préstamos hipotecarios: no son sólo abusivos los gastos comprendidos en la STS de 23 de diciembre de 2015 (gastos, efectos y plazos)", Centro de Estudios de Consumo (CESCO), enero 2017, disponible en: $\quad$ http://centrodeestudiosdeconsumo.com/images/gastos.pdf

AGÜERO ORTIZ, A.: "Cláusula de gastos en la STJUE de 16.7.2020: ¿más gastos restituibles; extensión del plazo para instar la restitución y condena en costas si la cláusula se declara abusiva?" Centro de Estudios de Consumo (CESCO), julio 2020, disponible en: 
http://centrodeestudiosdeconsumo.com/images/Clausula de gastos en la STJUE de 16.7.2020.pdf

AGÜERO ORTIZ, A.: "STJUE de 16 de julio de 2020: procede restituir íntegramente los gastos de formalización del préstamo hipotecario y declarar la abusividad de la comisión de apertura", Revista Jurídica sobre Consumidores y Usuarios, vLex, núm. especial, septiembre 2020.

ÁLVAREZ OLALLA, Ma. P.: "Cláusula suelo, interés moratorio, vencimiento anticipado e imposición de gastos a consumidor en el préstamo hipotecario", La Ley mercantil, n. ${ }^{\circ} 35,2017$.

BALLUGERA GÓMEZ, C.: "Distribución de gastos en la hipoteca y comisión de apertura. Comentario y resumen de la STJUE de 16 julio 2020", Revista de Derecho vLex, n. ${ }^{\circ} 195,2020$.

BALLUGERA GÓMEZ, C.: "Cinco sentencias para moderar el abuso en los gastos hipotecarios. Breve comentario de urgencia de la STS 46/2019, de 23 enero", Revista de Derecho vLex, n.o 177, 2019.

CARRASCO PERERA, Á.: "Retroactividad de la nulidad, procedimiento extrajudicial de reembolso de intereses por cláusulas suelo y el problema de la cosa juzgada", Centro de Estudios de Consumo (CESCO), enero 2017, disponible en: http://www.centrodeestudiosdeconsumo.com/images/CONDICIONES_GENERALES_ DE_LA_CONTRATACION/Clausula-suelo-y-cosa-juzgada.pdf (última consulta: 102-2021).

CASTILLO MARTÍNEZ, C. C.: "Sobre la nulidad de la cláusula de gastos en los préstamos hipotecarios con consumidores", Actualidad civil, n.o 9, 2017.

FERNÁNDEZ SEIJO, J. Ma: "Deben restituirse los gastos de tasación como efecto derivado de la nulidad de la cláusula gastos? De ser así, la restitución ha de total o parcial", Revista de consumo y empresa, n. ${ }^{\circ}$ 10, 2019.

GÁMEZ GUMERSINDO, C.: "Préstamos hipotecarios. Abusividad de la cláusula relativa a los gastos de formalización de la hipoteca, imputados de forma genérica al consumidor", Revista de Derecho, Empresa y Sociedad (REDS), n. ${ }^{\circ}$ 10, 2017.

GÓMEZ POMAR, F.; ARTIGOT GOLOBARDES, M.: "Costes, precios y excedente contractual en el control de la contratación de consumo, especialmente la hipotecaria", $A D C$, tomo LXXIII, 2020, fasc. I, pp, p. 77.

MARÍN LÓPEZ, M. J.: "El prestatario tiene derecho a recuperar íntegramente los gastos de gestoría tras la nulidad de la cláusula de gastos del préstamo hipotecario. Comentario a la STS 26 de octubre de 2020", Centro de Estudios de Consumo (CESCO), noviembre 2020, disponible en: http://centrodeestudiosdeconsumo.com/images/El prestatario tiene derecho a re cuperar integramente los gastos de gestoria tras la nulidad de la clausula de gastos del prestamo hipotecario.pdf (última consulta: 10-2-2021). 
MARÍN NARROS, H. D.: "Nulidad de la condición general de asunción de gastos de los préstamos hipotecarios y consecuente distribución y devolución de los mismos (notaría y registro de constitución y cancelación de la hipoteca, tasación y gestoría) conforme a las SSTS de 23 de diciembre de 2015, de 23 de enero de 2019 y resto de jurisprudencia del Tribunal Supremo y de las Audiencias Provinciales", Revista Crítica de Derecho Inmobiliario, n. ${ }^{0}$ 773, 2019, p. 1668.

MARTÍN FABA, J. Ma.: "La vinculación entre la acción declarativa de nulidad de cláusula suelo y la de restitución de intereses hace que ambas deban ejercitarse conjuntamente", Centro de Estudios de Consumo (CESCO), septiembre de 2017, disponible en: http://centrodeestudiosdeconsumo.com/images/Vinculacion_entre_accion_de_nulid ad_de_cl\%C3\%A1usula_suelo_y_restitucion_de_intereses.pdf (última consulta: 102-2021).

MARTÍNEZ GÓMEZ, S.: "Las expectativas de recuperación del 100\% de los gastos Hipotecarios, generadas por la STJUE 16.07.2020 y la SAP de las Palmas de 21.07.2020, han caído en saco roto tras ratificar el TS su doctrina sobre el reparto de los gastos", Centro de Estudios de Consumo (CESCO), septiembre 2020, disponible en:

http://centrodeestudiosdeconsumo.com/images/Las expectativas de recuperaci\% C3\%B3n del 100 de los gastos hipotecarios han caido en saco roto tras ratifi car el TS su doctrina sobre el reparto de los gastos.pdf (última consulta: 10-22020).

MATE SATUÉ, L. C.: "Transparencia y abusividad de la cláusula de gastos en los préstamos para adquisición de vivienda", Revista Crítica de Derecho Inmobiliario, n. ${ }^{\circ}$ 772, 2019, p. 931.

RIBÓN SEISDEDOS, E.: "Cláusula Suelo y reclamación de gastos hipotecarios. Acciones para su eliminación y devolución de cantidades indebidamente percibidas", Editorial Sepín.

RODRÍGUEZ ACHÚTEGUI, E.: "Tras la doctrina del TJUE: ¿sigue siendo santa la cosa juzgada?", Revista Aranzadi Doctrinal, n.o 4, 2017.

SANJUÁN, E.: "Deben restituirse los gastos de tasación como efecto derivado de la nulidad de la cláusula gastos? De ser así, la restitución ha de total o parcial", Revista de consumo y empresa, n. ${ }^{\circ} 10,2019$. 